\title{
A MODEL TO DESIGN MULTIMEDIA CONTENT FOR INTERACTIVE DOCUMENTATION OF ARCHITECTONIC RESEARCH AND CASE STUDY PROJECTS
}

\author{
Víctor Manuel Martínez López ${ }^{1}$ \\ Jorge Sosa Oliver ${ }^{2}$ \\ Fernando Omar Reyes Peralta ${ }^{3}$
}

\begin{abstract}
Creating multimedia content for the presentation and register of an architectural project means a synthesis effort to design the information that must be resumed to present a project, or the architectonic documentation in this area of knowledge. One case study is presented to show the advantages of the interactive digital tools, demonstrating how architectural content is visually communicated, manipulating plans, schemes and diagrams among other representations, and the way this information is encoded by means of architectonic floor plans, elevations, sections and spatial volumes, with the objective to communicate the idea of the project in a more efficient and didactic way. Technical requirements are also discussed to understand how this content is created showing its advantages and disadvantages and the viability so that an architect can really create this kind of multimedia content presenting all the documents and representations generated in an architectural project.
\end{abstract}

Keywords: multimedia, architecture, visual communication

\footnotetext{
${ }^{1}$ V.M. Martínez ( $\square$ vmartin_1@yahoo.com.mx ) Benemérita Universidad Autónoma de Puebla, Facultad de Arquitectura, Av.Sn.Claudio y Cto.CU, Puebla, México e-mail: vmartin 1@yahoo.com.mx. Is an architect with PhD. Degree on Visual Communication by the Universidad Politécnica de Catalunya, Barcelona, España. Currently full time Research Professor at the Facultad de Arquitectura at the Benemérita Universidad Autónoma de Puebla, México, member of the Sistema Nacional de Investigadores México.

${ }^{2}$ J. Sosa

Full time Research Proffesor. Benemérita Universidad Autónoma de Puebla, Cto. CU, Puebla, México

${ }^{3}$ F.O. Reyes

Student of Master Degree in Architectonic Design. Benemérita Universidad Autónoma de Puebla, Cto. CU, Puebla, México
} 


\subsection{Introduction}

In the architectural profession, when a project is completed, a series of graphic documents are generated, these are representations in the form of plans and codified in the language of architecture, this means architectural floor plans, elevations, sections and constructive details, among others. And the typical support for presentation is a printed paper plan (Fig.0). Today is essential presenting this information in a digital way, in order to store it, and to economize in physical space for example in the case of a library.

The problem begins when an architect tries to organize in a single media all these information, because an architectural floor plan can be stored in a CAD drawing format, which requires an specific application in order to be visualized, or a document of construction like an schedule which generally requires a word processor visualizer, and in the same way a virtual walkthrough which generally demands an specific codec of video compression to be shown. All of these digital information about a project becomes difficult to handle, most of the time because of technical issues of compatibility among platforms to show or present the information.

This research proposes a method to design and present information using one single solution, created by a multimedia integrator so that this helps to visualize in a more complete and practical way, all of these documents and representations that are generated in the architectural project.

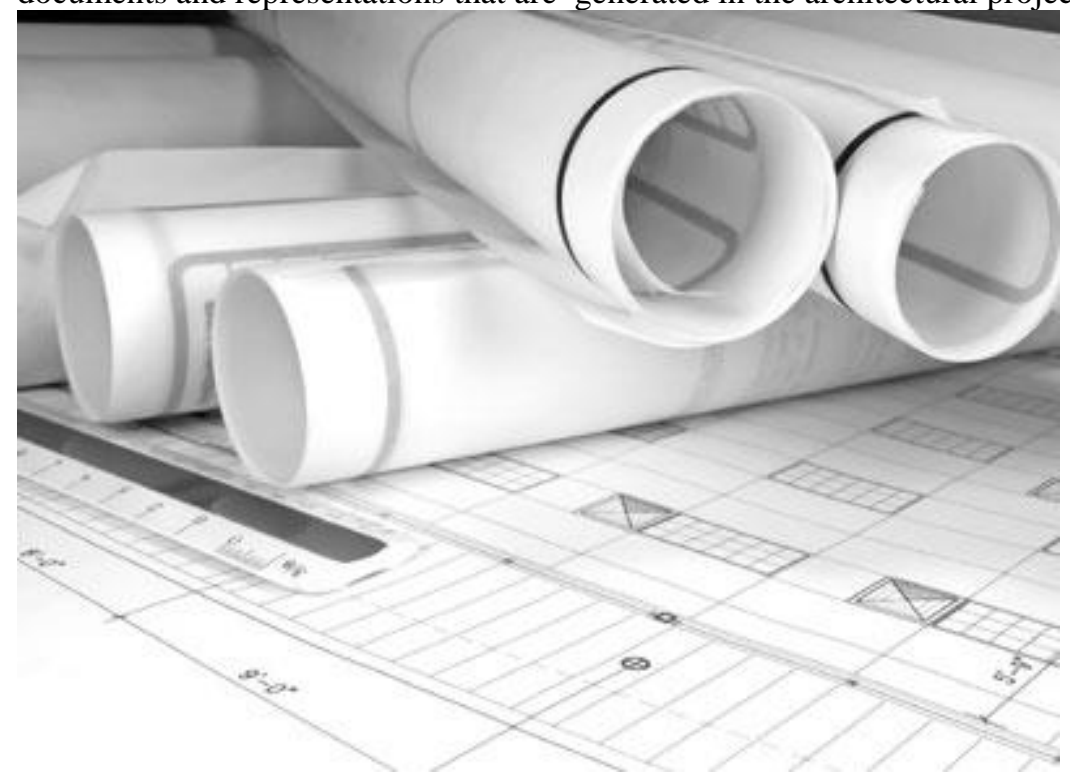

Fig. 0 Typical printed floor plans and architectural representations

\subsection{The Multimedia Presentation}

For this research a multimedia presentation is considered a graphic register which contains the following:

- Images for the visual experience, observing in a passive way.

- Video to perceive movement or change in time, in a dynamic way.

- Audio to enrich and complement the sensorial experience.

- Interaction between the user and the information using an interface that allows feedback.

In order to start working with all these media, some general considerations are proposed:

- Good documentation of the subject or project research.

- A storyboard or script which will act as guide to organize or plan the content. 


\subsection{Information Design}

If we consider that the goal is to design the access to architectural information content, in platforms of shared digital information, then what initially is proposed is to have a clear objective for the design of this information.

So what is shown next is a typical example of an architectural content generated in a project. This documented project is about an old market in the city of Braga, in Portugal originally projected by the famous architect Eduardo Souto de Moura.

The objective of this kind of multimedia register, was to show the change and actualization of use for this building, because it originally was a market (Braga market) and the changed to be a cultural center, so this is what defined the objective of the information design: the change of use. (Fig.1)

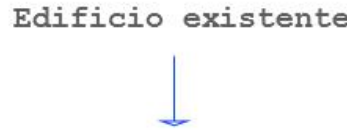

Mercado

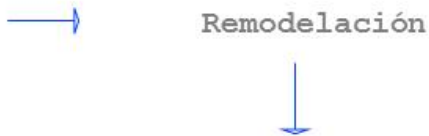

Centro cultural
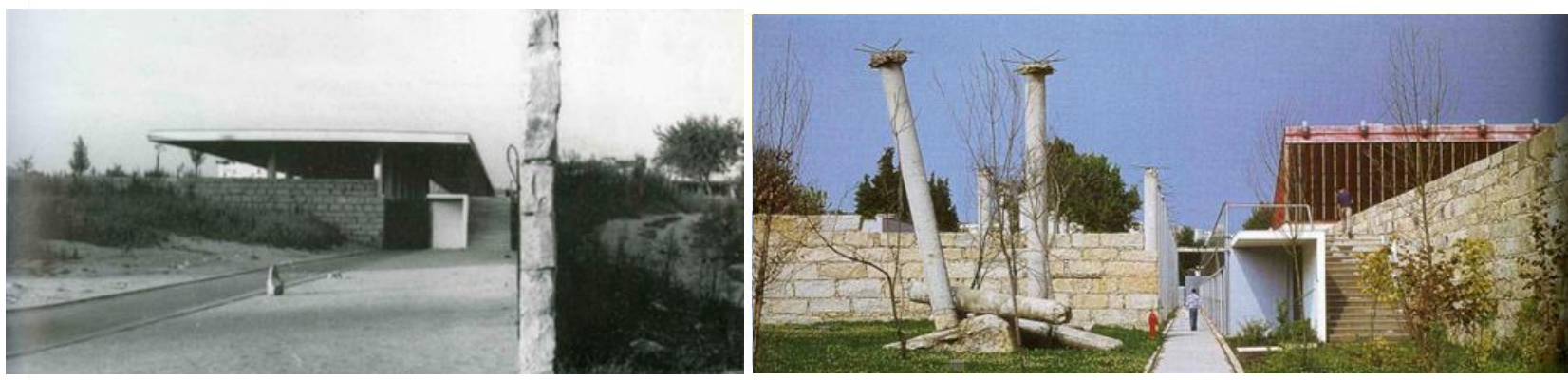

Objetivo:

ilustrar el cambio

Fig.1 The objective was to show the change of use in a building

Consequently this project was documented, from its original use, using floor plans, and existing photographs, found in books compilations, monographs and specialized magazines. (Fig.2)

- Imágenes

- Planos

- Fotos
Revistas especializadas

Libros y monografías
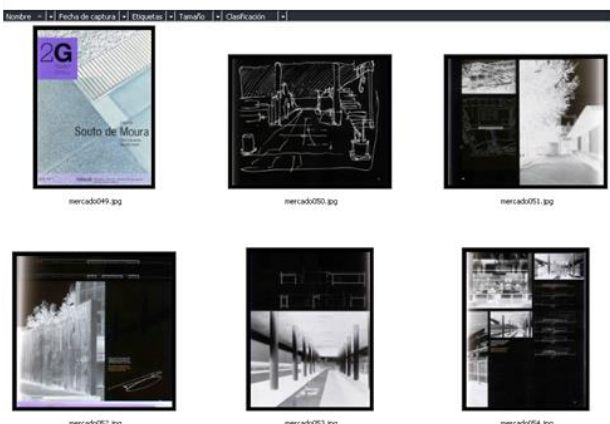
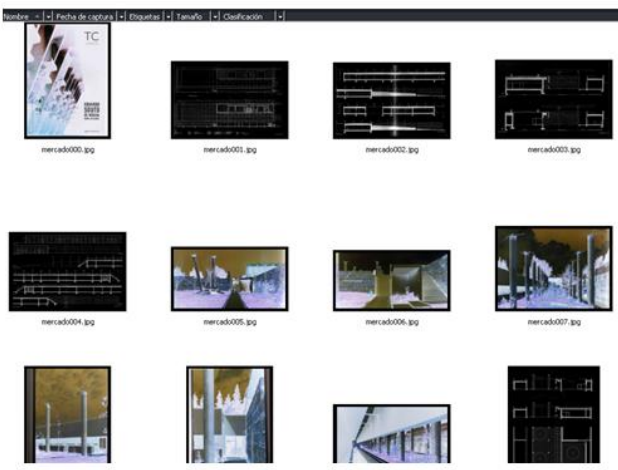

Fig.2 The case study is documented, extracting images and floor plans. 
Then a storyboard or a script is done in order to decide how this initial presentation would be designed, the audiovisual content that should be included and the thematic information to be explored, etc. (fig.3)
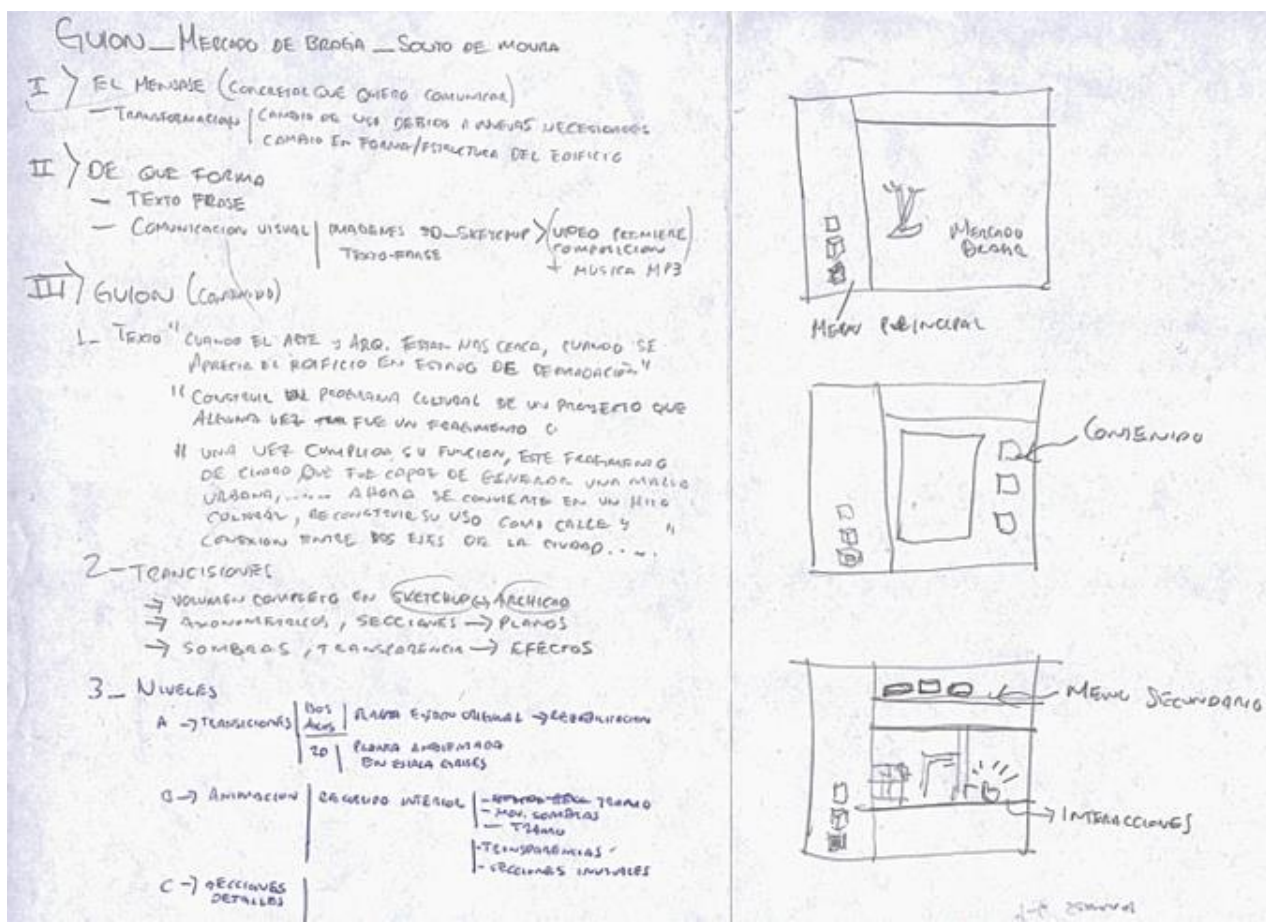

Fig. 3 An script is done in order to design the elements of the interface

Initially, and according to the decisions of the script, a "presentation screen" is proposed. It was important to include a video as a summary of the project (a passive observation solution) (Fig.4)

For the design of the main interface screen a lateral area was designated, and the remaining area was to be used as a display information of the content. The multimedia integrator used was the Autoplay Media Studio Pro v8.0, which is a very intuitive software that doesn't require prior knowledge of programming or information scripting.

Some evocative phrases were chosen from Eduardo Souto de Moura about this project and the general idea of the architectural ruin, and some technical data is shown, for example the construction and actualization date.

For the introduction video, although it is accessible immediately from the main menu, it was the last multimedia element to be generated, because it required additional material, from 3D renders of the model of the building, to the animations or walkthroughs.
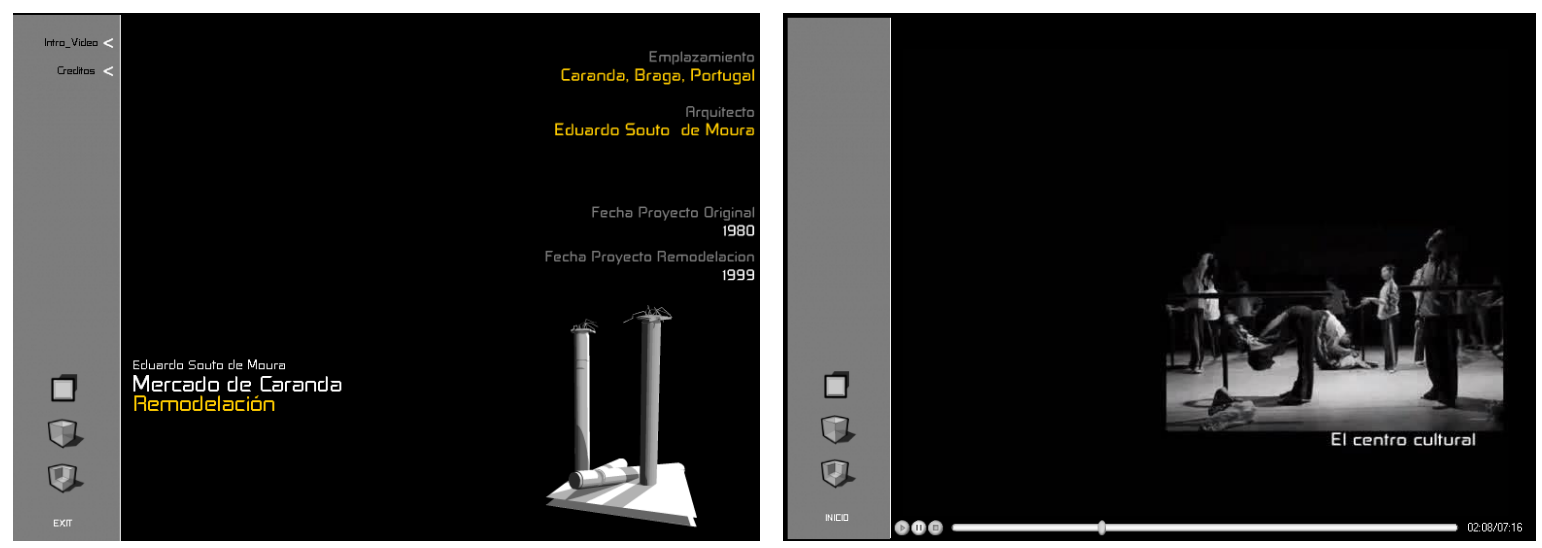

Fig.4 Design of the main presentation screen, and the introduction video. 
Furthermore, and according to the script, it was decided which one of the elements would be explored and manipulated by interactions, to present the idea of change. For the credits screen, it was necessary to include some software plug-ins and video codecs to play or visualize the audio and video content, resolving the problem of compatibility and distribution. (Fig.5)
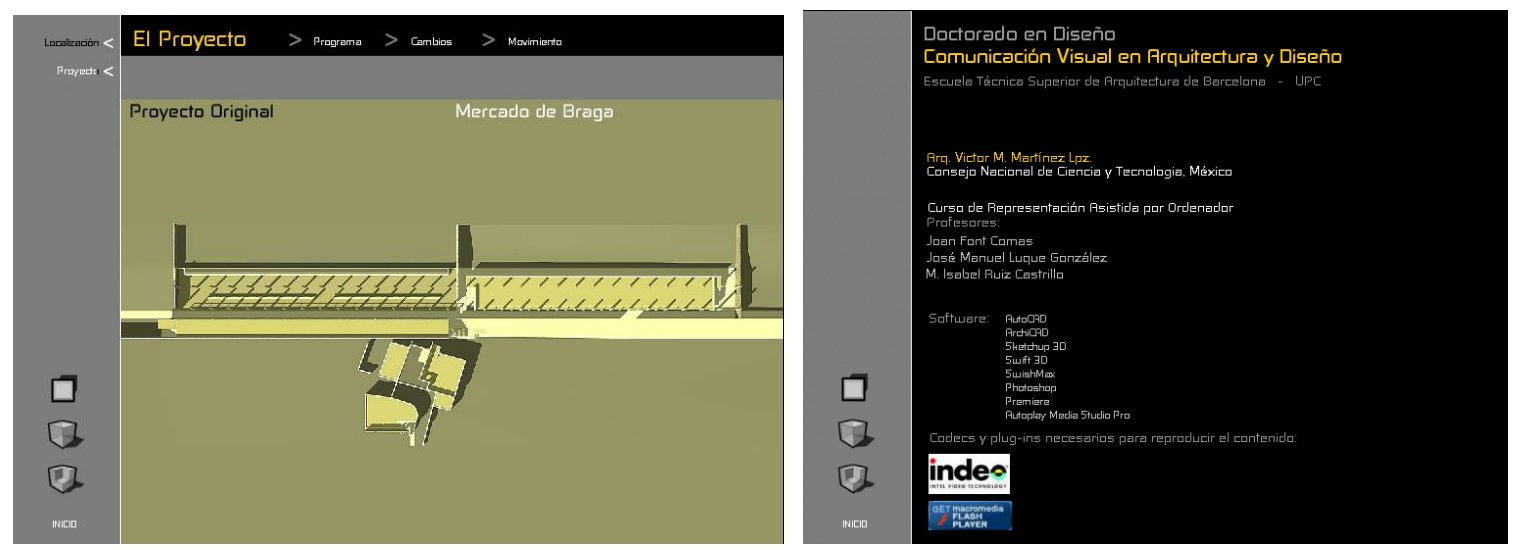

Fig.5 Exploration of content and menu design in the credits screen.

\subsection{Interface Design Criteria}

To have access to the information it was necessary to have some levels of visual control, mainly because of the way the documents of architecture are codified, in the form of bidimensional and tridimensional representations, so these levels were:

- $\quad 1$ st. Level, initial exploration content criteria

- 2D site (site plan, general floor plan) (Fig.6a)

- 3D geometry (spatial volume, perspective views) (Fig.6b)

- 2D/3D sections (internal functions, architectural program) (Fig.6c)
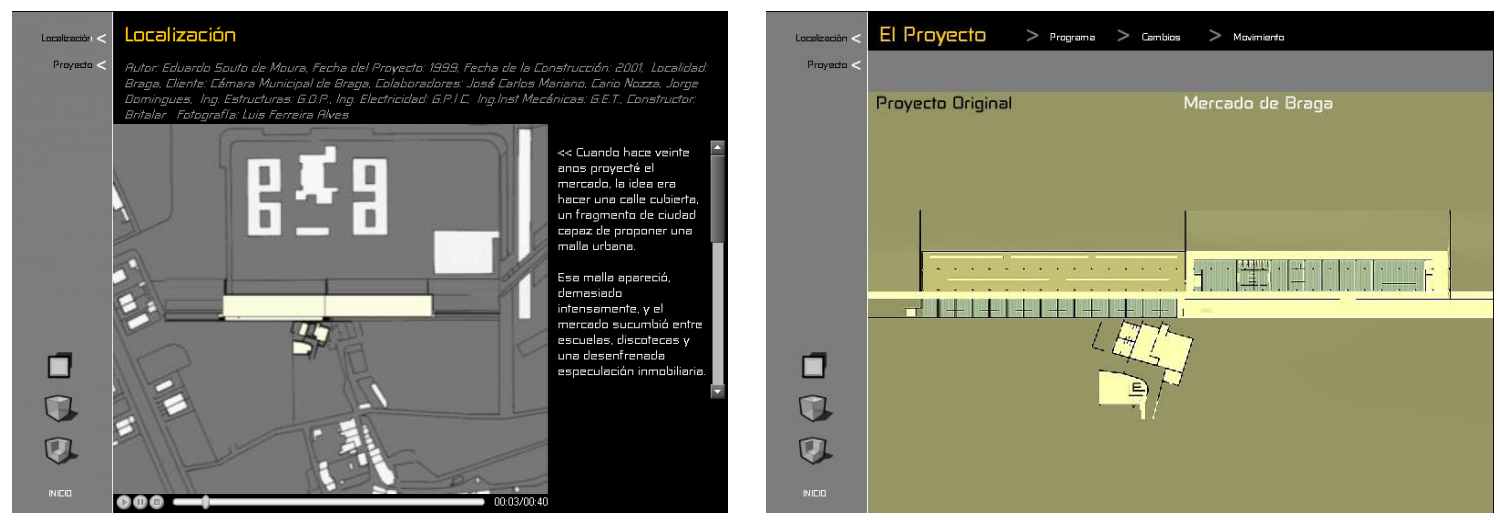

Fig.6a 2D Representations, showing the general floor plan, and urban site 


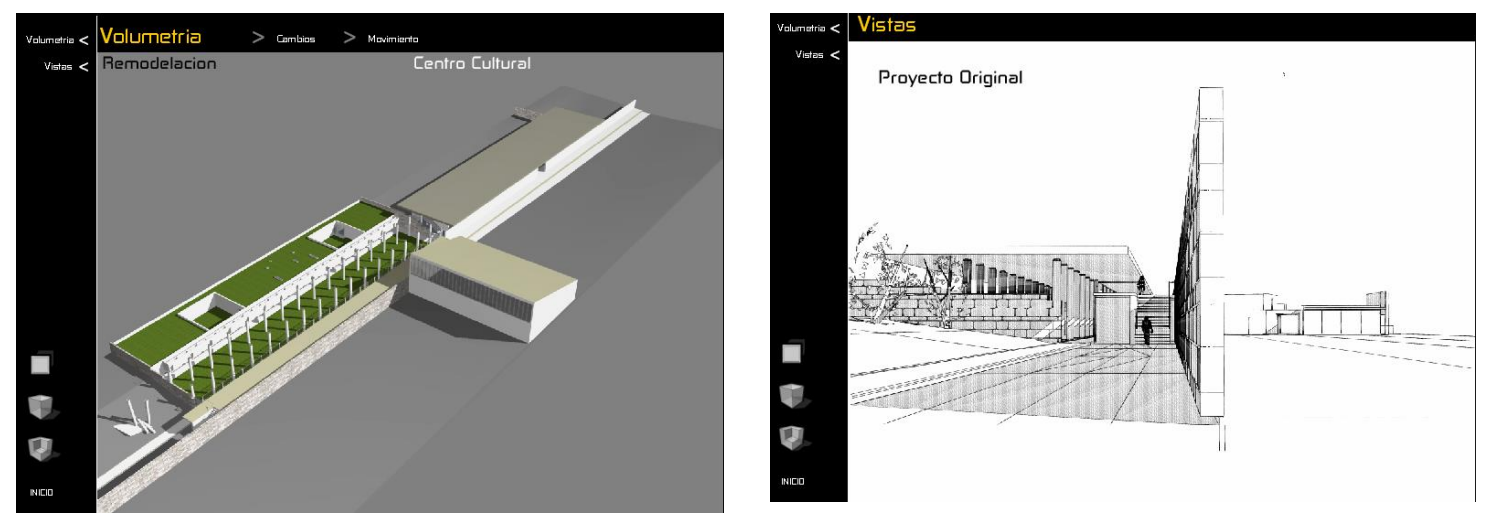

Fig.6b 3D representations, showing the spatial volume and perspective views
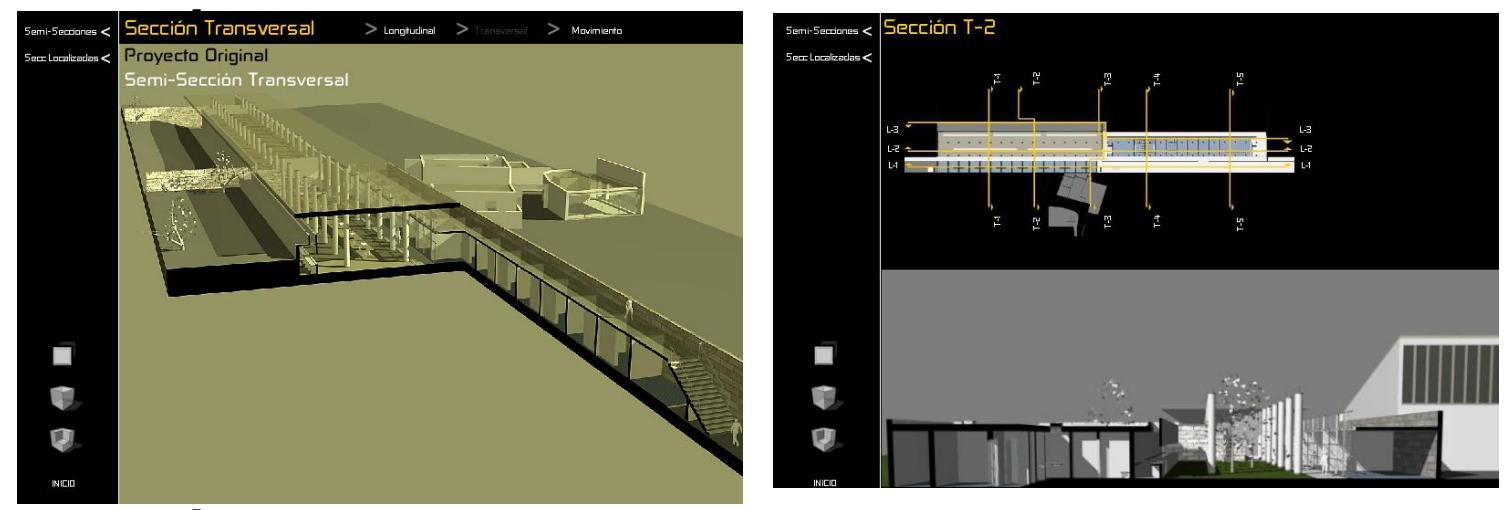

Fig. 6c Combination of 2D/3D present functions and internal architectural program

- $\quad 2^{\text {nd }}$ level, additional architectural details criteria (Fig.7)

- Showing the idea of change, in an interactive way

- Explain with movement or animation the internal function and form of a building
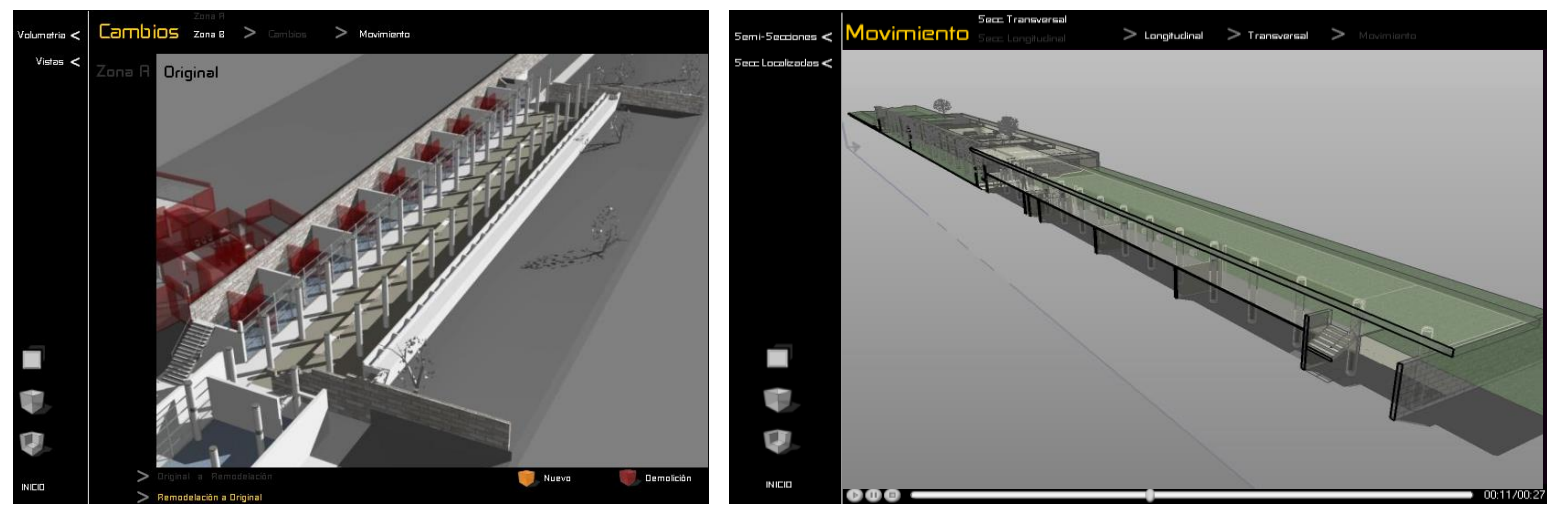

Fig.7 Combined representations in order to explain function and form with movement and interaction

\subsection{Work of modeling, register, edition, and multimedia effects}

Generally speaking for the presentation of the content, the process consisted on documenting the geometry of the project in order to model in digital 3D the building that once existed to be compared with the remodeling. So the content started by working with the floor plan on a CAD tool to draw with precision in $2 \mathrm{D}$, and consequently the work with the 3D spatial volume (using the AutoCAD software and the raster functions to draw the floor plans from a scanned image, then a conceptual schematic volume was done in 
Google Sketchup, and finally a parametric model was built on ArchiCAD to generate semi-sections and complex architectural sections).(Fig.8)
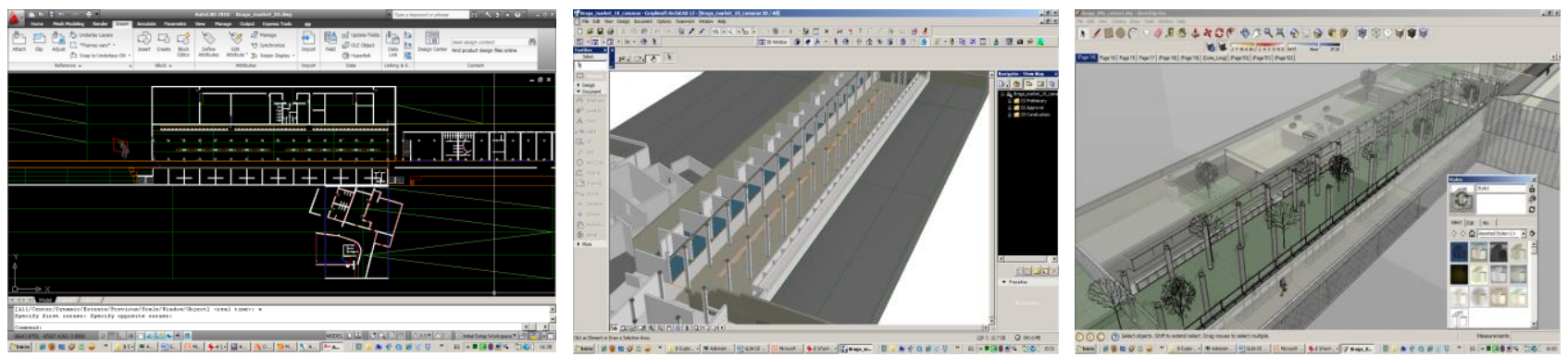

Fig.8 Modeling in CAD software

Then to have the final renders of the building, and the video, it was necessary to select and edit (with photoshop) some of the representative photos, showing the, before and after, in order to compare them and demonstrate the change using comparative slideshows, using the color in this stage was important to show the new bulding. As for the video, an editor was used (adobe premiere) to create a virtual walkthrough of 5 minutes explaining all this process of change, so the goal here was the creation of a single shot camera movement. (Fig.9)

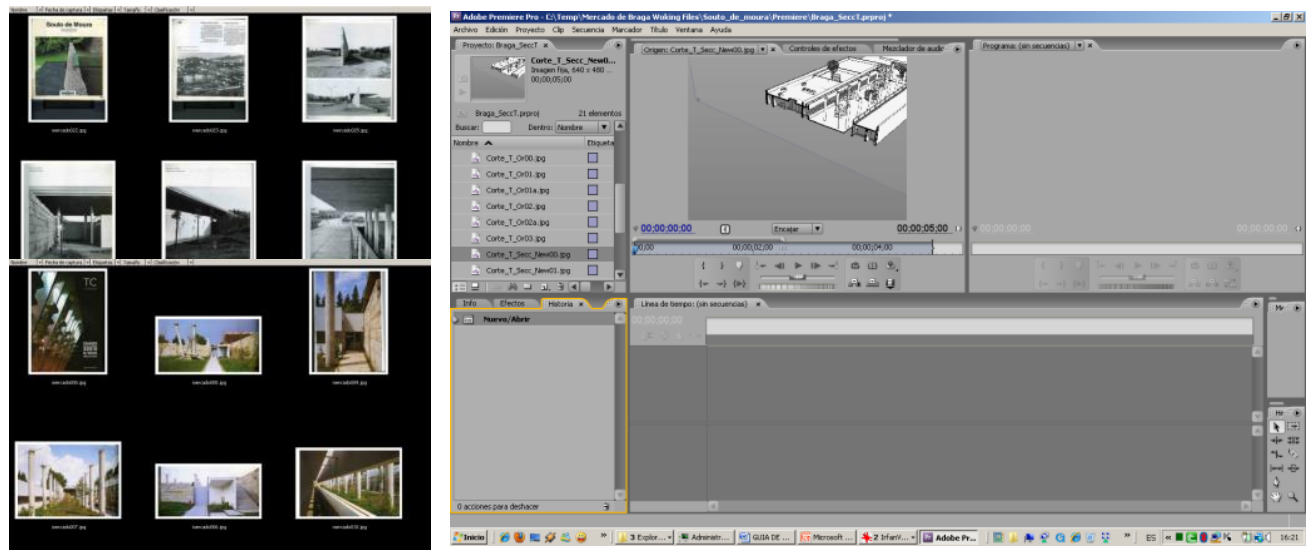

Fig.9 Working with the image and video sequence walkthrough

For the dynamic representations, a conceptual register was chosen according with the visual architectonic codification, showing simple volumetric representations so that it looked like a technical drawing (which was done using Swift3D) applying this criteria to the iconic elements of the cultural center, specifically the columns in the form of evocative ruins.(Fig. 10)

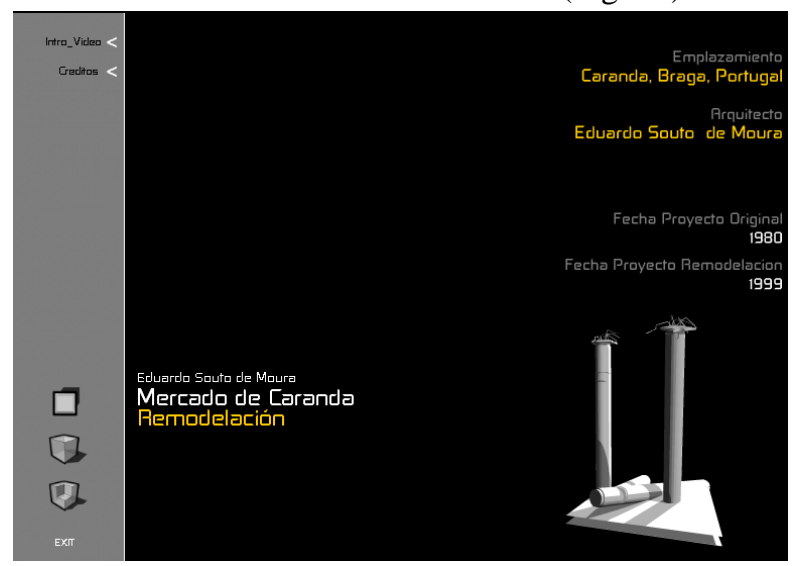

Fig.10 Conceptual 3D representation of the representative elements 
For the additional effects or post-production, a specific typography was used to present with dynamic transitions (using the Swishmax application) to have an aspect of dynamism in the multimedia content. In the same way it was necessary to retouch some photos to enhance elements of interest as localization of the building in the site. (Fig.11)
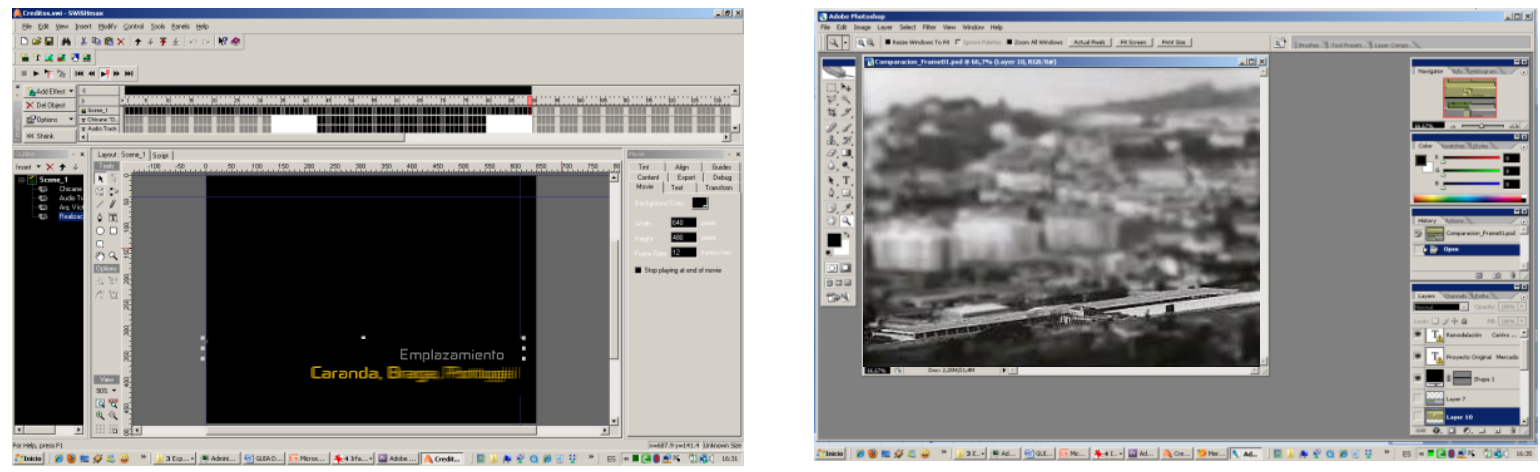

Fig.11 Dynamic transitions of text and visual effects on potos

Speaking about the interactive content, some technical difficulties were found when using and converting file formats, for example the use of a scaled raster image to draw with precision the floor plans and general volume, besides the work of importing and make compatible all of the the 2D/3D formats between different CAD applications and modelers.

\subsection{Multimedia Integration}

For the final steps of assemblage, the work lasted around 15 days from learning to use the software Autoplay Media Studio, and at the same time the general content was created and modeled. Some local tools of this software were used to generate the interactive menus, buttons, and transitions of images and screens using templates. So using this software allowed the process of the information design a much more intuitive workflow, compared with other commercial applications on the market, for example comparing it with Adobe Flash, which implies a larger learning curve and with less compatibility results.

Finally a general integration of documents was achieved in a single multimedia presentation, with all the technical issues resolved, because all of the information and content is included in a single application resolving the problems of compatibility. (Fig.12)

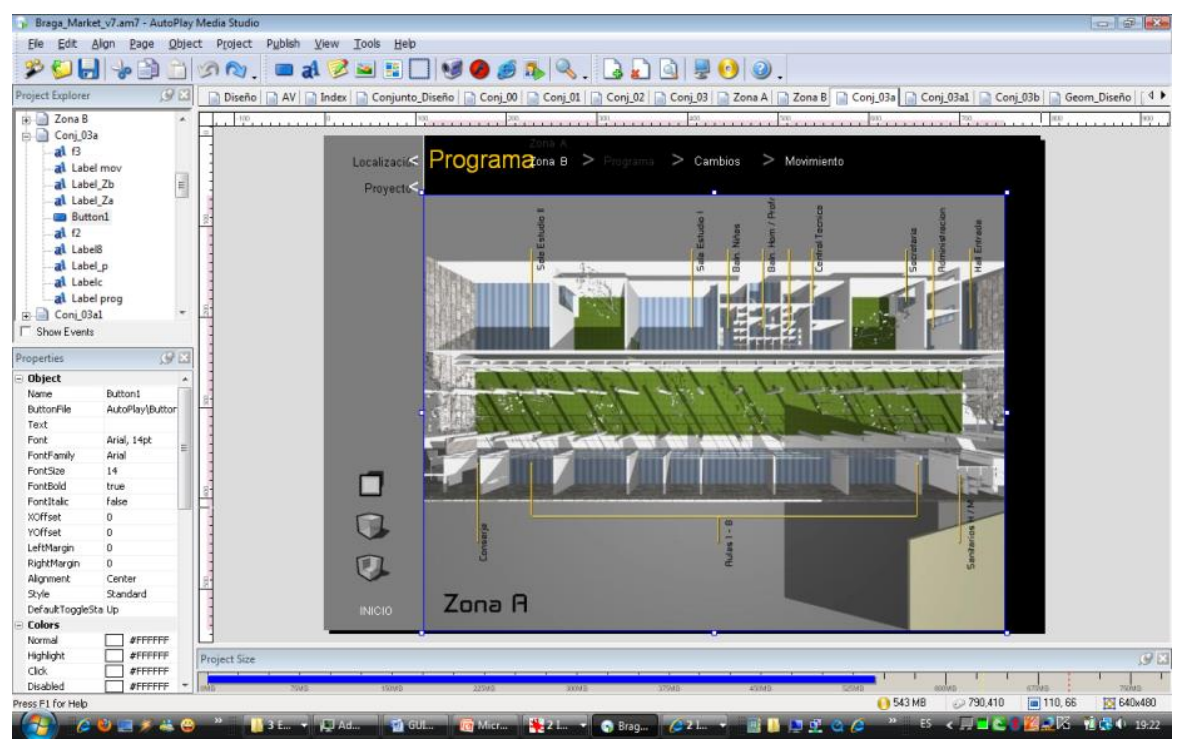

Fig. 12 Assemblage of the multimedia with the main application showing interactions 


\subsection{Discussion of Results}

Due to the great amount of documents generated in an architectural project, it is difficult to codify and present these in a single digital document, and because of scarce the training on these tools of architects to program or create this type of digital content, all of these documents remain disperse and requires multiple conventional media or digital platforms for the presentation, so this research shows how with a minimum of training on these multimedia integrating tools it is possible that an architect could create projects for presentations or for storing and register $[\mathbf{3 , 4 , 5}$. This kind of multimedia presentations are scarce in this field of knowledge, some of the existing are only audiovisual and or catalogs or slideshows of renders, so this research proposes a more complete integration in a single product of multimedia communication that it is not only demonstrative but it is interactive $[\mathbf{1 , 2}]$.

\subsection{Conclusions}

When designing the information, the interactions and the codification of content with the help of a multimedia integrator, it is concluded that it can be applied in two cases, in a practical way to present a typical architectural project on the one hand, and on the other hand this method can be used in a more documental way, when doing a research with an academic focus to be indexed or stored in a catalog or in a file [6, 7].

It is also suggested the necessity to train the architect in the usage of these tools to create multimedia content without reaching the extreme of programing, but only to know how to design the information in a more precise way and use these digital tools intuitively and not necessarily for commercial use, but in a more didactic way.

Finally it is proposed a model of multimedia codification as an example to further registers and presentation of projects and architectural research. This model implies a series of steps following this experience:

- It is essential a good and exhaustive initial documentation about the project or theme.

- Sticking to the initial script reduces time in the making of content because preliminary objectives are established step by step.

- If there is enough quantity of material to work with there should always be an important amount of visual richness.

- It is important a final step of selection of material to be presented because not all of the information can be included, and it is necessary an effort of synthesis.

- Finally it is interesting the result of experimentation with the design of the interface, of course without complicating it too much, to interact with the information in a simple and effective way.

\subsection{References}

1. Marton, P. (1996). Pedagogic conception of interactive multimedia learning systems. Perfiles Educativos, (72) (in spanish).

2. Saito, K. E., \& Röhmer-Liztmann, M.(2001). Multimedia for the architectural imagination (in spanish).

3. López García, G. (2007).Desing for architectural projects and information architecture. Valencia: Alfa Delta Digital (in spanish).

4. Art Museum Carrillo Gil. (1997).Creation in motion: architecture, sculpture, photograph, graphics, alternative media, multimedia, painting, video: 7th. exhibition of assistant scholars, 1995/1996. Museo de Arte Contemporáneo (in spanish).

5. Jaramillo de Sara L., et-al.(2002). Development of an integral multimedia CD in the Documentation Center IAPH. Écija. An historic city under the architectonic sign (in spanish).

6. Blanco Caballero, M. et-al.(2003). Study of the dihedral system by means of a multimedia tutorial (in spanish).

7. Salazar Bestard, L. et-al (2002). ReGraf. Interactive software for the learning-teaching of graphic representation in the architectural career (in spanish). 